\title{
Machine Vibration induced Underwater Acoustic Radiation
}

Wei-Hui Wang

Professor, Department of System Engineering and Naval Achitecture National Taiwan Ocean University, R.O.C.

Jia-Horng Liou

Ship Inspector, Keelung Harbor Bureau, R.O.C.

\section{Robert Sutton}

Reader, Department of Mechanical and Marine Engineering, University of Plymouth, UK

Ben Dobson

Chief Design Engineer, Devonport Royal Dockyard, Plymouth,UK.

Follow this and additional works at: https://jmstt.ntou.edu.tw/journal

Part of the Engineering Commons

\section{Recommended Citation}

Wang, Wei-Hui; Liou, Jia-Horng; Sutton, Robert; and Dobson, Ben (2000) "Machine Vibration induced Underwater Acoustic Radiation," Journal of Marine Science and Technology. Vol. 8: Iss. 1, Article 4.

DOI: 10.51400/2709-6998.2451

Available at: https://jmstt.ntou.edu.tw/journal/vol8/iss1/4

This Research Article is brought to you for free and open access by Journal of Marine Science and Technology. It has been accepted for inclusion in Journal of Marine Science and Technology by an authorized editor of Journal of Marine Science and Technology. 


\section{Machine Vibration induced Underwater Acoustic Radiation}

Acknowledgements

The authors wish to thank the support from the National Science Council of the Republic of China under contract NSC 88-2611-E-019-008 for this project. 


\title{
MACHINE VIBRATION INDUCED UNDERWATER ACOUSTIC RADIATION
}

\author{
Wei-Hui Wang* Jia-Horng Liou** Robert Sutton*** Ben Dobson****
}

Keywords: fluid-structure interaction, coupled FEM/BEM, radiation pattern.

\section{ABSTRACT}

A coupled FEM/BEM for solving fluid-structure interaction problem in structure-borne noise propagation and underwater acoustic radiation is present in this paper. In order to improve the habitability and stealth low noise condition is required in various types of ships. One of the dominant components is the radiated airborne and underwater noise caused by ship hull vibration. Accordingly, the estimation of structure-borne sound characteristics of a ship is important in the design of a quieter ship-structure. The hull vibration response and pressure distribution on the wetted surface of a ship subjected to excitation sources can be analyzed by utilizing the developed method. Further discussions on the evaluation of surface complex power, radiation and reactance power have been conducted.

Two cases were studied, a submerged spherical shell subjected to a uniformly harmonic pressure excitation and a scale model of engine room structure subjected to machine excitations, to illustrate the applications of the analytical model. The surface pressure, the normal velocity on the wetted surface, the surface complex power, the radiation power, the reactance power, the vibrational displacement and the radiated underwater sound pattern have been computed. Comparison of the predicted results and that by measurement indicates that the numerical model is creditable. In addition, the effect on underwater acoustic radiation at the elastic mounts for the engine is discussed.

\section{INTRODUCTION}

Structure-borne sound power is predominantly transmitted to a sound carrying structure from a source via a number of contact points. In turn, the noise and vibrations are propagated in the structure possibly causing sensitive equipment to vibrate or to cause undesired radiated noise. In principle, this may be avoided by

Paper Received May 21, 2000. Author for Correspondence: W. H. Wang. *Professor, Department of System Engineering and Naval Achitecture National Taiwan Ocean University, R.O.C.

**Ship Inspector, Keelung Harbor Bureau, R.O.C.

***Reader, Department of Mechanical and Marine Engineering, University of Plymouth, UK

****Chief Design Engineer, Devonport Royal Dockyard, Plymouth,UK. measures at source, in transmission, during propagation or at radiation. It is, of course, preferable to cope with the problems at the generation sites and thereby avoid more comprehensive and expensive measures later in the chain. To this point, the resilient mounts are utilized as an effective countermeasure to reduce noise and vibrational power transmitted from the source to sound receiver.

In reviewing noise transmission paths, we note that from the machinery room to other areas of the ship, there are three parallel paths: air, water, and structure, the latter being the most important. While structureborne noise is familiar, it takes an uncommon form in ship hulls; compared to industrial environments, the hull is relatively homogeneous and long wave-guide whose transmission characteristics are affected by spatially periodic stiffening frames. Furthermore, the waterborne path is intimately couple to the structure-borne path, partially short-circuiting structural impedance discontinuities such as bulkheads, which, in the atmosphere, would constitute effective barriers to structure-borne noise propagation. Another peculiarity of hull is that, over much of the relevant frequency range, radiation loading is associated with inertia forces, exerted by the entrained mass of water, which modify hull plating response. Because of the high sound velocity of water, the coincidence frequency of surface ship hull plating lies in the ultrasonic range. Flexural waves therefore radiate from areas where wavenumber conversion occurs, viz. driving points and impedance discontinuities. Once launched, the waterborne acoustic signal suffers propagation losses which are small compared to those encountered in the atmosphere.

The main features of shipboard noise have been studied in the last decades. The power flow concept was proposed and used to explain the relation between the mobility and structure-borne sound transmission [1]. The effectiveness of resilient mounts to abate the engine vibration was modeled in $[2,3]$. Furthermore a coupled multi-path mobility model using the four-pole parameter method was established to predict the structureborne sound transmission between a source structure 
and a receiving structure in $[4,5]$. The sound radiation from a vibrating body was firstly dealt with by helmholtz equation in [6]. Meanwhile the boundary integral equations for vibrating sources located in interior or exterior domain and on boundary were established separately. Some fictitious eigenfrequencies and singular values could be appeared in dealing with the exterior domain problems. This phenomenon is essentially due to the numerical method. To improve the solution method a combind Helnholtz integral equation formulation (CHIEF) has submitted in [7, 8]. Underwater sound radiation from various vibrating submerged structures was studied in [9-16] by using a coupled finite element and variational boundary element technique. As a summary of these studies, the fluid-structure interaction effect showed predominant important in predicting the underwater sound radiation especially in low frequency vibrational radiation. It has been validated by experimental measurement in [17].

In this paper three main aspects of machine vibration radiating underwater sound are predicted and measured. They are the transfer mobility and power flow from a motor via resilient mounts, fluid-structure interaction effect in underwater acoustic radiation and the underwater radiation pattern.

\section{POWER FLOW ANALYSIS VIA RESILIENT MOUNTING}

Operational motions of engine and other machineries start the vibration, and the resilient mounts under the machinery seatings initiate the reduction efforts of noise control. The effectiveness of ioslation is defined as the measure of the power transmitted to the structure. This single quantity includes both the vibration parameters of force and velocity. Minimizing the power transmitted through an isolator is also consistent with the first step in any vibration control exercise, ie, to deal with the problem at the source. Normally, the resilient mounts are composed of elastic and viscoelastic materials and designed in various configurations.

The vibrational power fed into a structure for a multipoint mounting system can be calculated by utilizing the concept of effective mobility [1-5] of the source/ mount/receiver system and the source characteriztion as a force or a velocity. Furthermore, if the relations between the mobility function pertaining to the coupled and decoupled source/mount/receiver systems can be derived, then the effectiveness and performance of the mount can be identified.

\section{Mobility Theory}

Assume a mechanical system in which the har- monic force $F_{1}$ and the harmonic velocity $V_{1}$ were applied to the input end of the system and the force $F_{2}$ and the velocity $V_{2}$ were induced on the output end. The relations between state variables $V_{1}, F_{1}$ and $V_{2}, F_{2}$ are [3]:

$$
\left\{\begin{array}{l}
V_{1} \\
F_{1}
\end{array}\right\}=\left[\begin{array}{ll}
\alpha_{11} & \alpha_{12} \\
\alpha_{21} & \alpha_{22}
\end{array}\right]\left\{\begin{array}{l}
V_{2} \\
F_{2}
\end{array}\right\}
$$

where $\alpha_{11}, \alpha_{12}, \alpha_{21}$ and $\alpha_{22}$ are called the four-pole parameters [4] and

$$
\begin{aligned}
& \alpha_{11}=\frac{M_{11}}{M_{12}}, \quad \alpha_{12}=\frac{M_{12} M_{21}-M_{11} M_{22}}{M_{12}}, \\
& \alpha_{21}=\frac{1}{M_{12}}, \alpha=-\frac{M_{22}}{M_{12}}
\end{aligned}
$$

and $M(i=1,2 ; j=1,2)$ are the mobility functions.

If the subsystems $a$ and $b$ are linked in series, the two ends of each subsystems are 1,2 and 3, 4 respectively, as shown in Fig. 1(a), in which $F$ represents force and $V$ represents velocity. When the subsystems link together, then $V_{3}=V_{2}$ and $F_{3}=-F_{2}$. The tranfer relation of the state vectors between points 1 and 4 is:

$$
\begin{aligned}
\left\{\begin{array}{c}
V_{1} \\
F_{1}
\end{array}\right\} & =\left[\begin{array}{ll}
\alpha_{11} & \alpha_{12} \\
\alpha_{21} & \alpha_{22}
\end{array}\right]\left\{\begin{array}{l}
V_{2} \\
F_{2}
\end{array}\right\} \\
& =\left[\begin{array}{ll}
\alpha_{11} & \alpha_{12} \\
\alpha_{21} & \alpha_{22}
\end{array}\right]\left[\begin{array}{cc}
\alpha_{33} & \alpha_{34} \\
-\alpha_{43} & -\alpha_{44}
\end{array}\right]\left\{\begin{array}{l}
V_{4} \\
F_{4}
\end{array}\right\} \\
& =\left[\begin{array}{ll}
\alpha_{11}^{\prime} & \alpha_{14}^{\prime} \\
\alpha_{41}^{\prime} & \alpha_{44}^{\prime}
\end{array}\right]\left\{\begin{array}{l}
V_{4} \\
F_{4}
\end{array}\right\}
\end{aligned}
$$

It requires that $F_{4}=0$ since 4 is the receiving point and 1 is the driving point. Thus,

$$
M_{41}(\omega)=\frac{V_{4}}{F_{1}}=\frac{1}{\alpha_{41}^{\prime}}=\frac{1}{\alpha_{21} \alpha_{33}-\alpha_{22} \alpha_{43}}=\frac{M_{12}+M_{34}}{M_{22} M_{33}}
$$

From equation (4), it can be seen that the transfer mobility of the combined system $\left(M_{41}\right)$ is not simply the combination of the transfer mobilities $\left(M_{12}\right.$ and $\left.M_{34}\right)$ of the two subsystems. The linking point mobilities $\left(M_{22}\right.$ and $M_{33}$ ) of the subsystems play a predominant role for determining the total transfer mobility. As a damping material is introduced into the input end of the subsystem $b$, such as Fig. 1(b) which represents the improved system of Fig. 1(a), then the mobility $M_{33}$ increases significantly, It follows from equation (4) that the total transfer mobility $M_{41}$ is reduced. In other 


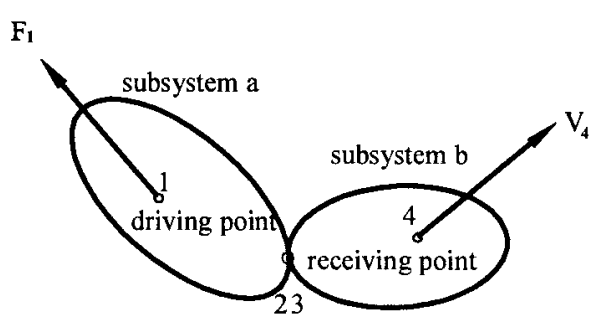

(a)

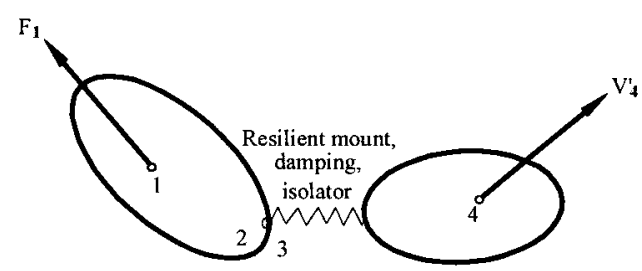

(b)

Fig. 1. System before and after installation of isolator damping material.

words, to reduce the total transfer mobility, it requires the introduction of a larger mobility than the original one. This is the basic principle for a good structureborne noise attenuation result that has to properly design the structure on both sides of a resilient mount with small mobility than that of the mount itself.

\section{Power Flow}

The instantaneous vibration power input $\left(P_{\text {inst }}\right)$ to a structure is defined as the product of the excitation force $(F)$ and the associated velocity $(V)$. At any point on a structure, the velocity and force can be related via frequency response mobility (or impedance) functions, so that the power can be expressed in the following forms:

$$
P=\frac{1}{2}\{F\}^{T} \operatorname{Re}[M]\{F\}
$$

or

$$
P=\frac{1}{2}\{V\}^{T} \operatorname{Re}[Z]\{V\}
$$

From expressions (5) and (6), it is clear that the power injected into a structure by the machine is dictated by the excitation force or velocity exerted by a machine and the mobility or impedance characteristics of the supporting structure. The characterization of an engine as a "velocity source" will now be considered .

In practical measurements by utilizing a FFT analyser, the power can be found by using the force spectrum density function $G_{f f}$, the vibration velocity spectrum density function $G_{v v}$, or the cross power spectrum density function $G_{f v}$, which can be expressed as:

$$
P(\omega) G_{f f} \operatorname{Re}[M]=\operatorname{Re}\left[G_{f v}\right]=G_{v v} \operatorname{Re}[Z e]
$$

The driving point impedance matrix and the receiving point impedance matrix and the transfer impedance matrix for well-installed system can be obtained as:

$$
\begin{aligned}
& {\left[Z_{\text {input }}\right]=\left[Z_{11}\right]=\frac{\left[M_{44}\right]}{\left[M_{11}\right]\left[M_{44}\right]-\left[M_{14}\right]\left[M_{41}\right]}} \\
& {\left[Z_{\text {output }}\right]=\left[Z_{44}\right]=\frac{\left[M_{11}\right]}{\left[M_{11}\right]\left[M_{44}\right]-\left[M_{14}\right]\left[M_{41}\right]}}
\end{aligned}
$$

$$
\left[Z_{\text {transmit }}\right]=\left[Z_{41}\right]=\left[Z_{41}\right]=\frac{-\left[M_{14}\right]}{\left[M_{11}\right]\left[M_{44}\right]-\left[M_{14}\right]\left[M_{41}\right]}
$$

Substituing $\left[Z_{\text {input }}\right],\left[Z_{\text {output }}\right]$ and $\left[Z_{\text {transmit }}\right]$ into equation (7), the input power, output power and transmitted power can be calculated respectively by:

$$
\begin{aligned}
& P_{\text {input }}=G_{V_{A} V_{A}} \operatorname{Re}\left[Z_{\text {input }}\right] \\
& P_{\text {output }}=G_{V_{B} V_{B}} \operatorname{Re}\left[Z_{\text {output }}\right] \\
& P_{\text {transmit }}=G_{V_{A} V_{A}} \operatorname{Re}\left[Z_{\text {transmit }}\right]
\end{aligned}
$$

Thus the general methodology for obtaining the power fed into a receiving structure from the excitation sources of a engine via the contact points is derived.

\section{MODELLING SOUND RADIATION FROM A SHIP STRUCTURE}

\section{Fluid-Structure Interaction}

When a ship is floating in water and subjected to machine induced vibrating forces $\{f\}$, then the equations of motion of the ship structure can be expressed in matrix form as:

$$
[M]\{\ddot{x}\}+[C]\{\dot{x}\}+[K]\{x]=\{f\}-\{p\}
$$

where $[M],[C]$ and $[K]$ represent the mass, damping and stiffness matrices respectively. $\{f\}$ is the acoustic loading transmitted from the machine mountings which is gained by the mobility theory and charaterising the vibrational sources as velocity sources. While $\{p\}$ represents the hydrodynamic pressure which can be 
only applied to the surfaces of the structure contacted with water and shall be analysed by the coupling algorithm which is a combination of finite element $(F E)$ and boundary element $(B E)$ methods.

If the internal structural damping effect can be neglected and the displacement vector $\{x\}$ of the structure is divided into $\left\{x_{n}\right\}$, ie, the displacement of the interior structure as well as the tangential displacement on the water contacting surface as shown in Fig. 2, then equation (14) becomes:

$$
\left[\begin{array}{cc}
M_{n n} & M_{n i} \\
M_{i n} & M_{i i}
\end{array}\right]\left\{\begin{array}{c}
\ddot{x}_{n} \\
\ddot{x}_{i}
\end{array}\right\}+\left[\begin{array}{cc}
K_{n n} & K_{n i} \\
K_{i n} & K_{i i}
\end{array}\right]\left\{\begin{array}{c}
x_{n} \\
x_{i}
\end{array}\right\}=\left\{\begin{array}{l}
f_{n} \\
f_{i}
\end{array}\right\}-\left\{\begin{array}{l}
p \\
0
\end{array}\right\}
$$

\section{Coupling of the FE and BE Methods}

Consider a linear structure system put $\{x\}=$ $\{X\} e^{i \omega t}$ into equation (15) then,

$$
\left[\begin{array}{cc}
K_{n n} & K_{n i} \\
K_{i n} & K_{i i}
\end{array}\right]\left\{\begin{array}{c}
X_{n} \\
X_{i}
\end{array}\right\}-\omega^{2}\left[\begin{array}{cc}
M_{n n} & M_{n i} \\
M_{i n} & M_{i i}
\end{array}\right]\left\{\begin{array}{l}
X_{n} \\
X_{i}
\end{array}\right\}=\left\{\begin{array}{c}
f_{n} \\
f_{i}
\end{array}\right\}-\left\{\begin{array}{c}
p \\
0_{i}
\end{array}\right\}
$$

The second equation in (16) is:

$$
\begin{aligned}
\left(\left[K_{i n}\right]\right. & \left.-\omega^{2}\left[M_{i n}\right]\right)\left\{X_{n}\right\}+\left(\left[K_{i i}\right]-\omega^{2}\left[M_{i i}\right]\right)\left\{X_{i}\right\} \\
= & \left\{f_{i}\right\}
\end{aligned}
$$

and $\left\{X_{i}\right\}$ can be expressed in terms of $\left\{X_{n}\right\}$ from equation (5.62) as :

$$
\begin{aligned}
\left\{X_{i}\right\} & =\left(\left[K_{i i}\right]-\omega^{2}\left[M_{i i}\right]\right)^{-1}\left(\left\{f_{i}\right\}-\left(\left[K_{i n}\right]\right.\right. \\
& \left.\left.-\omega^{2}\left[M_{i n}\right]\right)\left\{X_{n}\right\}\right)
\end{aligned}
$$

Substituting (18) into equation (16),

$$
\begin{aligned}
\left(\left[K_{n n}\right]\right. & \left.-\omega^{2}\left[M_{n n}\right]\right)\left\{X_{n}\right\}+\left(\left[K_{n i}\right]-\omega^{2}\left[M_{n i}\right]\right)\left\{X_{i}\right\} \\
= & \left\{f_{n}\right\}-\{p\}
\end{aligned}
$$

or

$$
\begin{aligned}
& \left(\left(\left[K_{n n}\right]-\omega^{2}\left[M_{n n}\right]\right)-\left(\left[K_{n i}\right]-\omega^{2}\left[M_{n i}\right]\right)\left(\left[K_{i i}\right]\right.\right. \\
& \left.\left.\quad-\omega^{2}\left[M_{i i}\right]\right)^{-1}\left(\left[K_{i n}\right]-\omega^{2}\left[M_{i n}\right]\right)\right)\left\{X_{n}\right\} \\
& \quad=-\left(\left[K_{n i}\right]-\omega^{2}\left[M_{n i}\right]\right)\left(\left[K_{i i}\right]-\omega^{2}\left[M_{i i}\right]\right)^{-1}\left\{f_{i}\right\} \\
& \quad+\left\{f_{n}\right\}-\{p\}
\end{aligned}
$$

Since the underwater acoustic pressure distribution radiated from a vibrating hull surface is governed by the Helmhotz equation:

$$
\nabla^{2} p(\vec{r}, \omega)+k^{2} p(\vec{r}, \omega)=0
$$

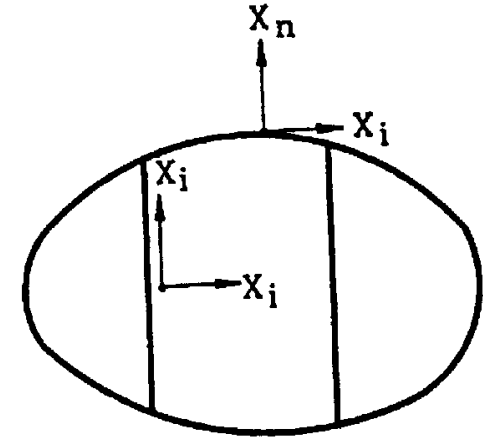

Fig. 2. Definition of $\left\{x_{n}\right\}$ and $\left\{x_{i}\right\}$.

and $p(\vec{r})$ can be expressed as :

$$
P(\vec{r})=\frac{1}{2 \pi} \int_{S_{s}}\left[P\left(\vec{r}_{s}\right) \frac{\partial P\left(\vec{r}_{s}\right)}{\partial n\left(\vec{r}_{s}\right)}-G\left(\vec{r}, \vec{r}_{s}\right) \frac{\partial P\left(\vec{r}_{s}\right)}{\partial n\left(\vec{r}_{s}\right)}\right] d S_{s}
$$

where

$\vec{r}=$ position vector in water;

$\vec{r}_{s}=$ position vector on immersed hull surface;

$n\left(\vec{r}_{s}\right)=$ normal direction vector at $\vec{r}_{s}$;

$\mathrm{S}_{\mathrm{S}}=$ immersed hull surface area;

$P(\vec{r})=$ underwater acoustic pressure amplitude at $\vec{r}$;

$G\left(\vec{r}, \vec{r}_{s}\right)=$ Green's function or the fundamental solution to Eq.(20), and

$$
G=\frac{e^{-j k r(x, y)}}{4 \pi r(x, y)}
$$

where

$$
r(x, y)=|x-y|=\sqrt{\left(x_{1}-y_{1}\right)^{2}+\left(x_{2}-y_{2}\right)^{2}+\left(x_{3}-y_{3}\right)^{2}}
$$

in which $x$ is the field point and $y$ is the source point.

The relation between $P(\vec{r})$ and the normal displacement $x_{n}$ on the hull surface must satisfy:

$$
\frac{\partial P\left(\vec{r}_{s}\right)}{\partial n\left(\vec{r}_{s}\right)}=-i \rho_{0} \omega v_{n}\left(\vec{r}_{s}\right)=\rho_{0} \omega^{2} x_{n}
$$

Utilizing the discretization technique with interpolating shape functions to the water contacting hull surface, equation (22) becomes :

$$
[A]\{P\}=[G]\left\{x_{n}\right\}
$$

Substituting equation (24) into (19), the governing equation for the combined $F E$ and $B E$ methods for the structure-borne noise transmission problem inboard ships can show to be: 

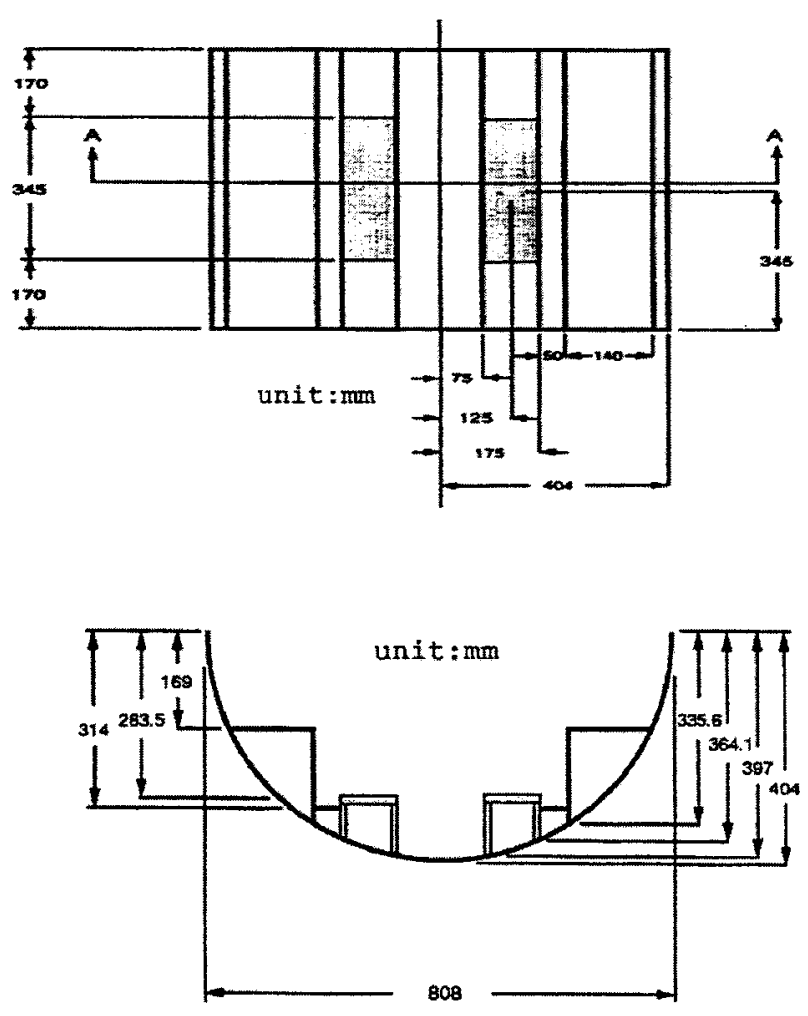

Fig. 3. Experimental model of an engine room.
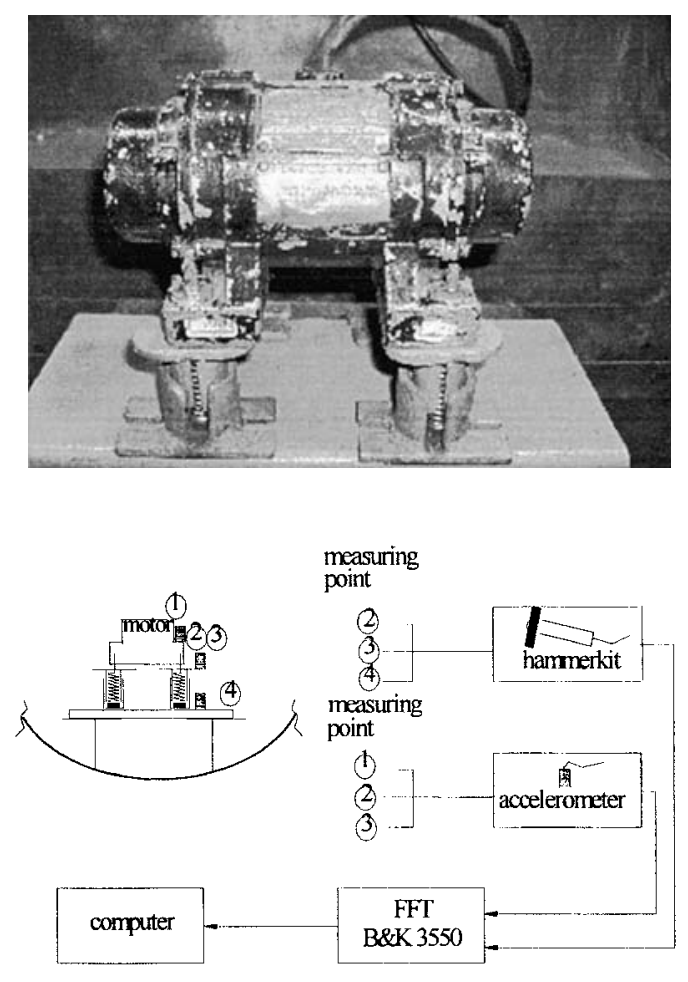

Fig. 4. Instrument arrangement for mobility measurement.

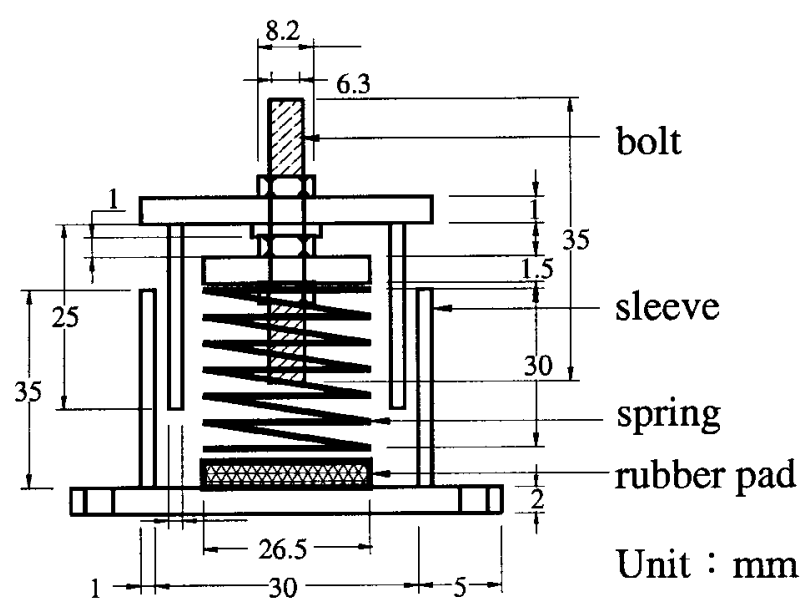

Fig. 5. Configuration of the sleeve type of resilient mount.

$$
\begin{aligned}
& {\left[\left(\left[K_{n n}\right]-\omega^{2}\left[M_{n n}\right]\right)-\left(\left[K_{n i}\right]-\omega^{2}\left[M_{n i}\right]\right)\left(\left[K_{i i}\right]\right.\right.} \\
& \left.\left.\quad-\omega^{2}\left[M_{i i}\right]\right)^{-1}\left(\left[K_{i n}\right]-\omega^{2}\left[M_{i n}\right]\right)\right\}\left\{x_{n}\right\} \\
& \quad+[A]^{-1}[G]\left\{x_{n}\right\}=\left\{f_{n}\right\}-\left(\left[K_{n i}\right]-\omega^{2}\left[M_{n i}\right]\right)\left(\left[K_{i i}\right]\right. \\
& \left.\quad-\omega^{2}\left[M_{i i}\right]\right)^{-1}\left\{f_{i}\right\}
\end{aligned}
$$

\section{COMPARISON OF NUMERICAL ANALYSIS AND MEASUREMENT}

\section{Description of Experiment Design}

To validate the accuracy of the mobility analysis and the FEM/BEM noise propagation models experiments were undertaken on a scale model of an engine room structure. This model with a length $808 \mathrm{~mm}$, as shown in Fig. 3, consists of two end bulkheads, four girders on the bottom, one bilge tank on each side. On the top of the girders there installed a bedplate and a stepless motor supported by four resilient mounts bolted on the bedplate. The motor was designed with a deliberate eccentric mass on the shaft. The arrangement of mobility measurement and the configuration of the resilient mount are shown in Figs. 4 and 5 respectively.

\section{Comparisons of Mobility and Vibrational Power}

The measured and predicted transfer mobility $M_{41}$ when the model being put in water and in air with and without rubber pad are compared in Figs. 6-9. The resilient mount effect on transfer mobility in water and in air are compared in Figs. 10 and 11 When the motor ran at a speed $1800 \mathrm{rpm}$, the rubber pad effect on the exciting vibration velocity and the transfer power at the input and output ends are shown in Figs. 12-19. From the results, it is evident that resilient mounts have the effects to reduce transfer mobility, vibratory velocity and vibrational power by an amount of 5-20dB, 2-5dB 


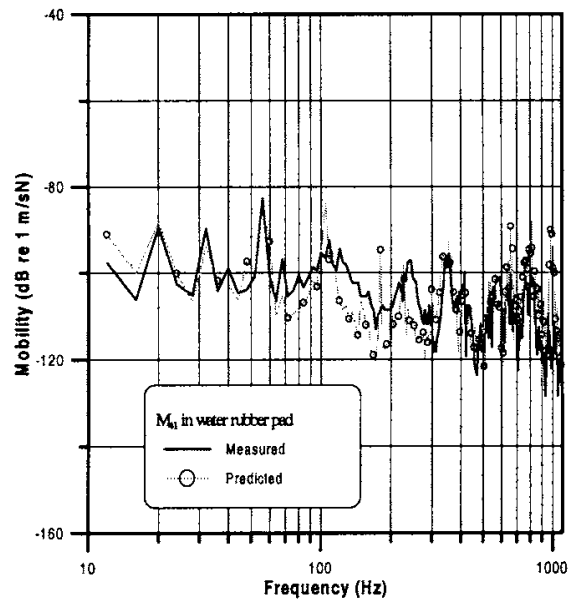

Fig. 6. Transfer mobility $M_{41}$ in water without rubber pad.

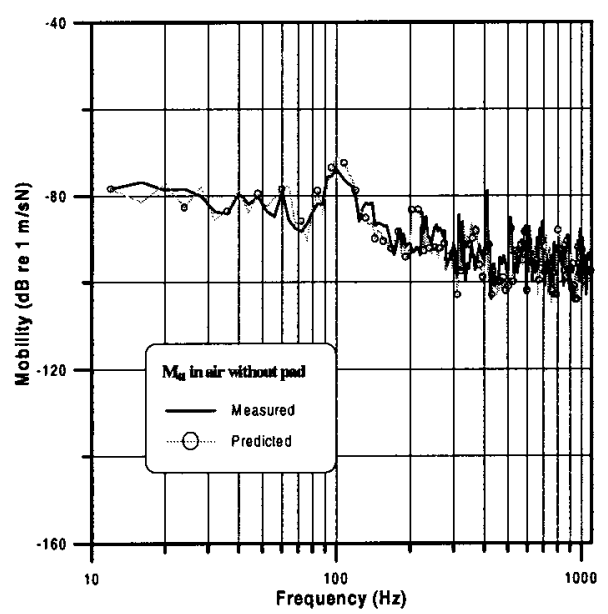

Fig. 7. Transfer mobility $M_{41}$ in air without rubber pad.

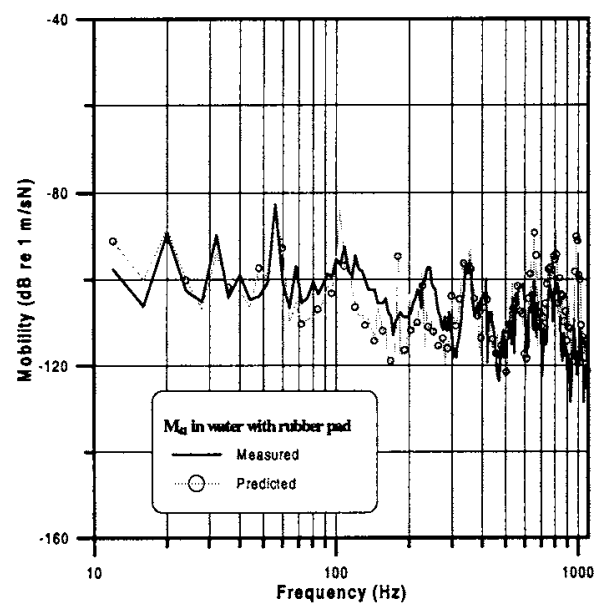

Fig. 8. Transfer mobility $M_{41}$ in water with rubber pad.

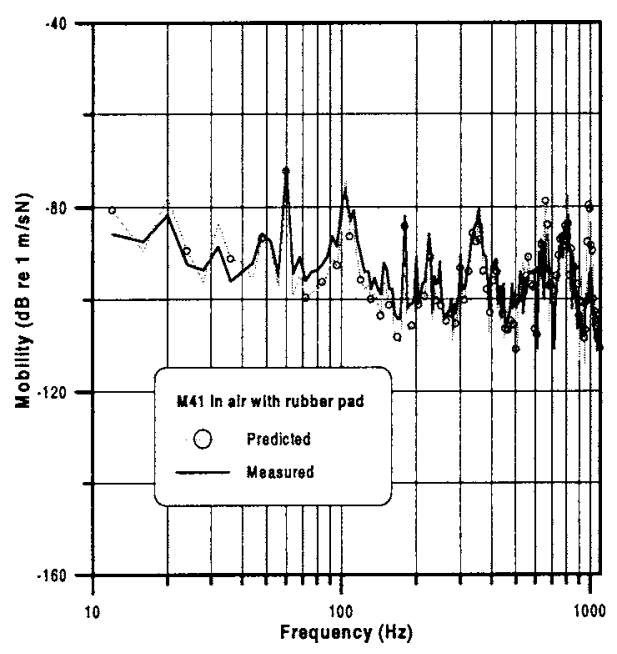

Fig. 9. Transfer mobility $M_{41}$ in air with rubber pad.

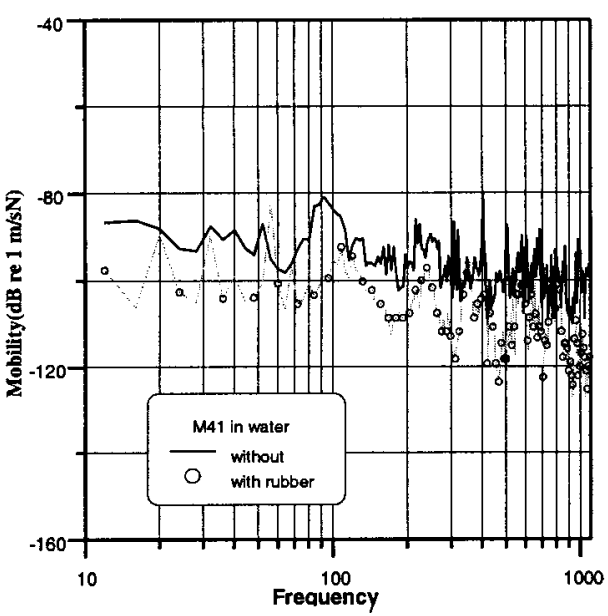

Fig. 10. Resilient mount effect on transfer mobitity in water.

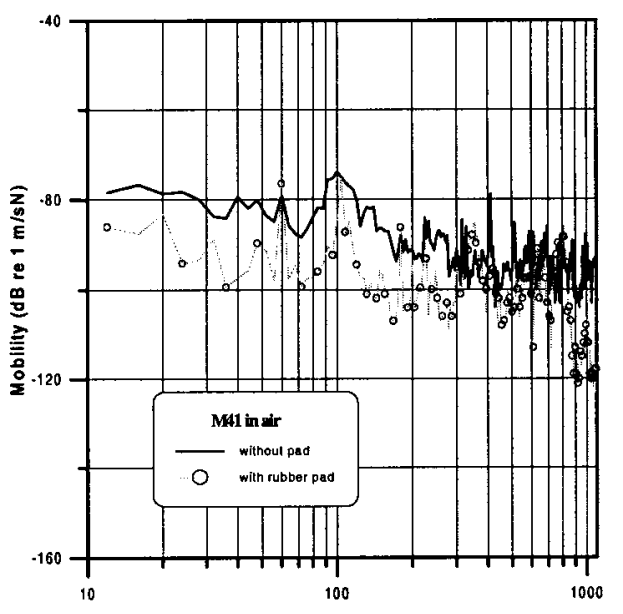

Fig. 11. Resilient mount effect on transfer mobitity in air. 


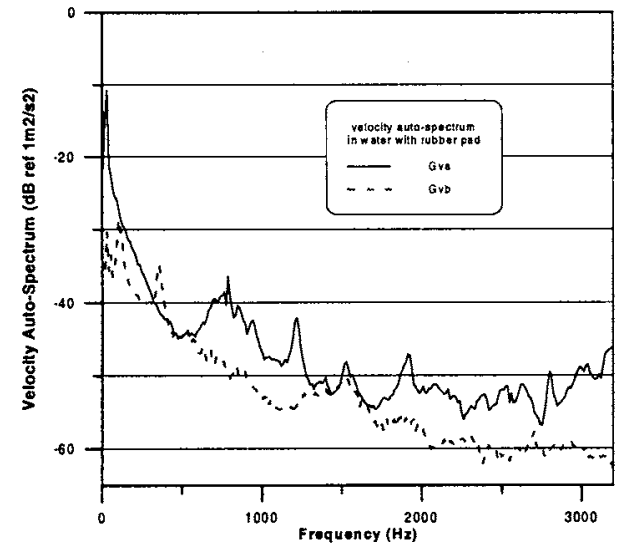

Fig. 12. Velocity auto-spectrum at input and output ends with rubber pad in water.

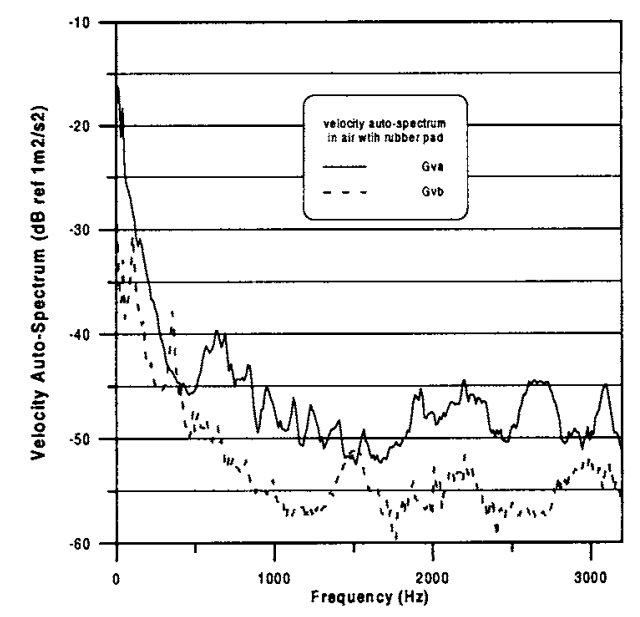

Fig. 13. Velocity auto-spectrum at input and output ends with rubber pad in air.

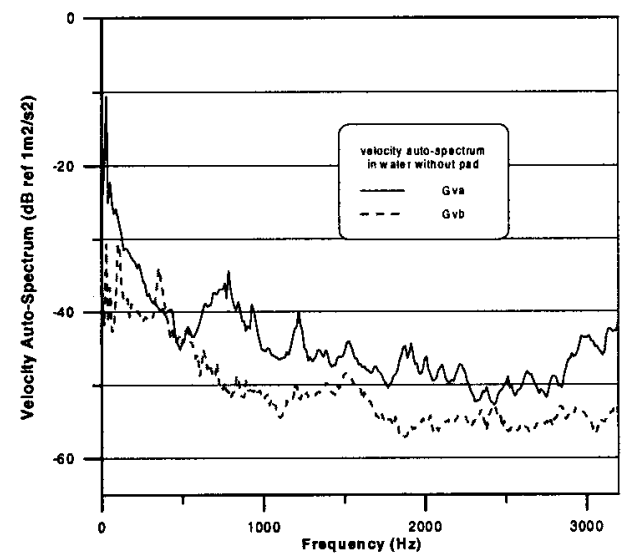

Fig. 14. Velocity auto-spectrum at input and output ends without rubber pad in water.

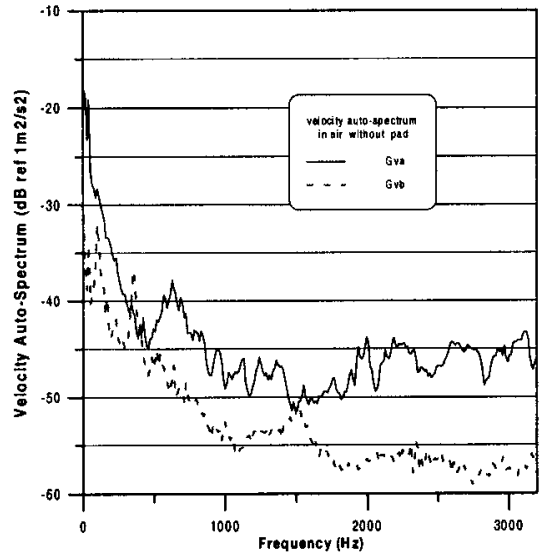

Fig. 15. Velocity auto-spectrum at input and output ends without rubber pad in air.

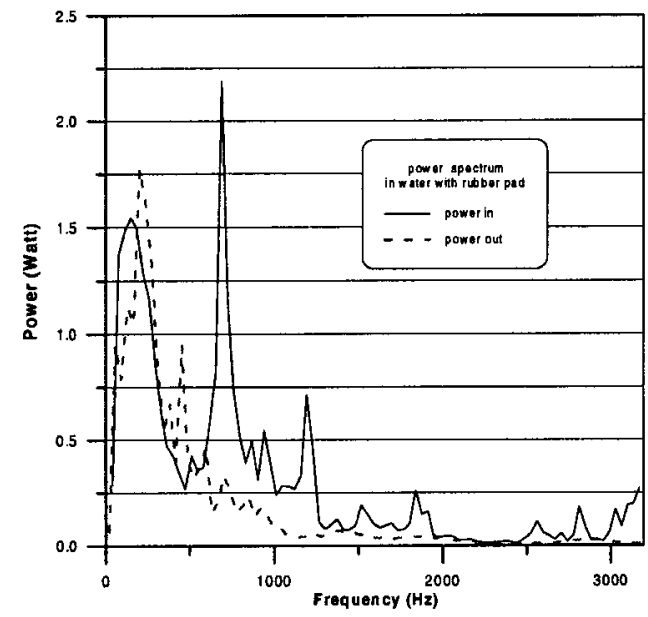

Fig. 16. Power spectrum at input and output ends with rubber pad.

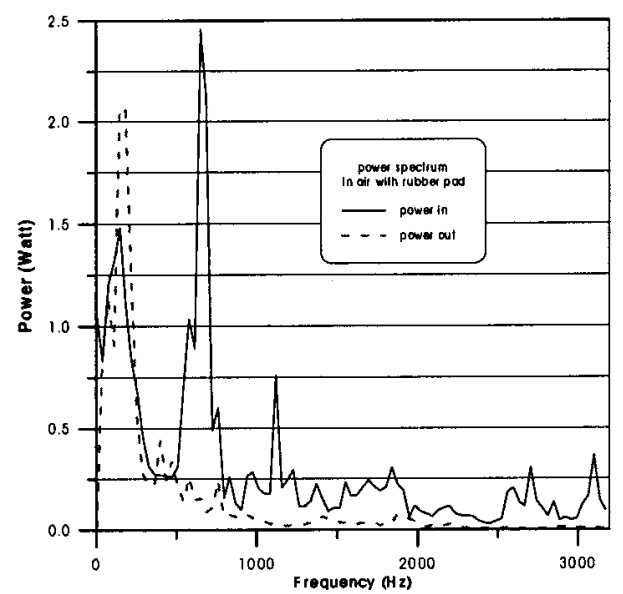

Fig. 17. Power spectrum at in put and output ends with rubber pad in air. 


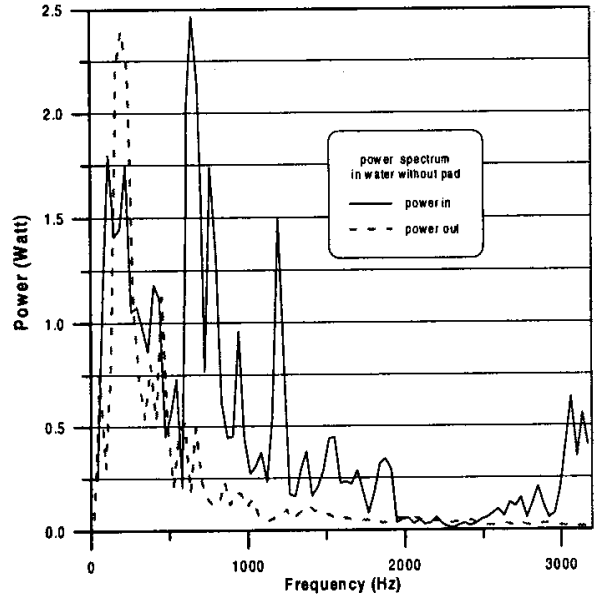

Fig. 18. Power spectrum at input and output ends without rubber pad.

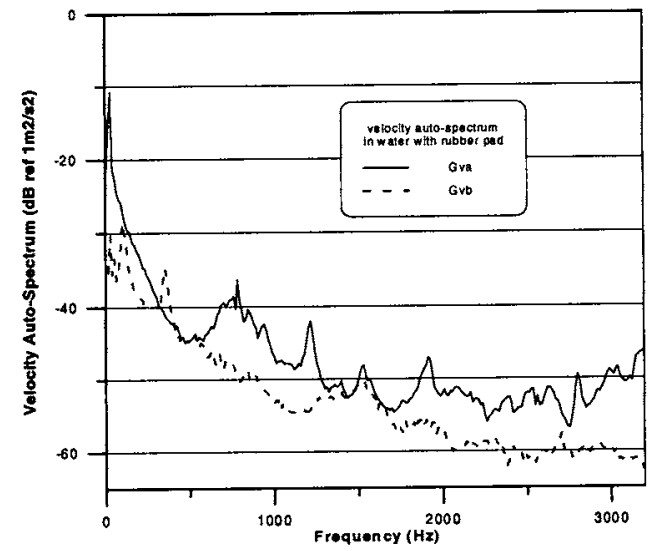

Fig. 19. Power spectrum at input and output ends without rubber pad in air.

and $10-40 \%$ respectively. The entrained mass of water apparently reduced the transfer mobility by an amount $5-10 \mathrm{~dB}$ in the lower frequency range.

\section{Validation of the Numerical Model}

Consider a submerged spherical shell of radius $1 \mathrm{~m}$ and thickness $3 \mathrm{~cm}$. When the shell subjected to a harmonic internal pressure of magnitude $1 \mathrm{~Pa}$, the analytical solution of the sound pressure and normal velocity on the surface of spherical shell can be found in [11] and [12]. Fig. 20 shows the FEM/BEM model. Comparisons of the numerical solutions of the spectra of surface pressure magnitude and the normal velocity magnitude are shown in Figs. 21 and 22. The coincidence of the curves validate the numerical model being credible.

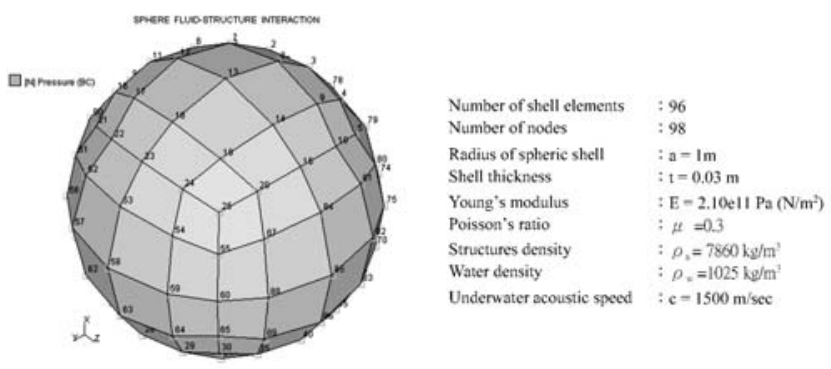

Fig. 20. Numerical model of a spherical shell.

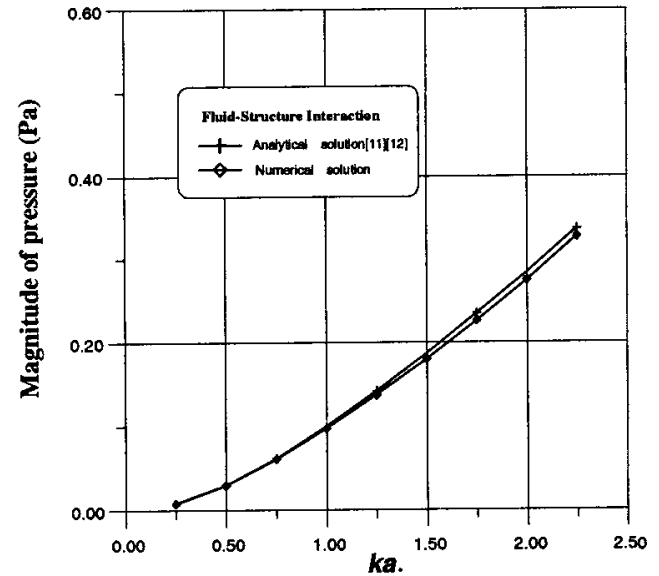

Fig. 21. Surface pressure magnitude spectrum on a spherical shell under unit harmonic internal pressure excitation.

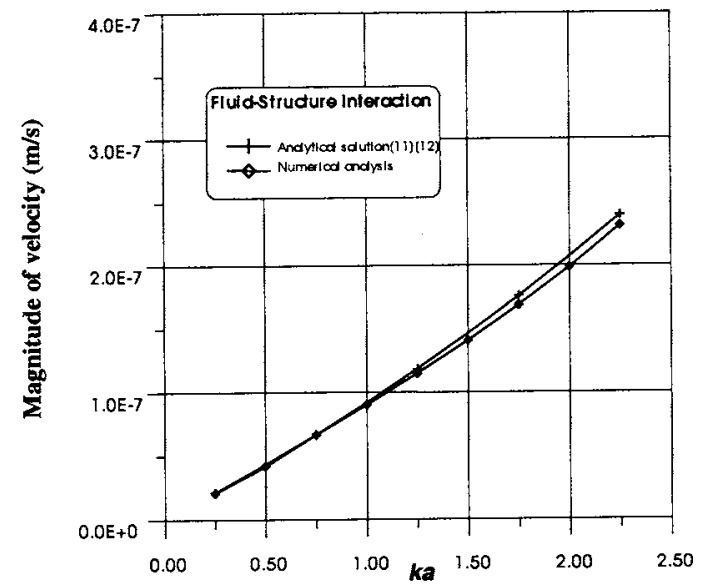

Fig. 22. Surface normal velocity magnitude spectrum on a spherical shell under unit harmonic unit internal pressure excitation.

\section{Predicted and Measured Underwater Sound Pattern}

The FEM/BEM mesh of the model structure were established as Figs. 23 and 24. When the scale model 


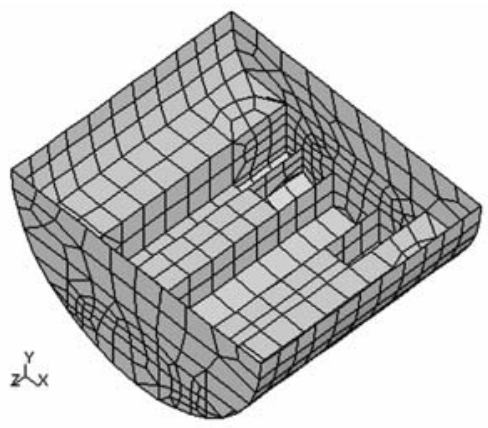

Number of shell elements $\quad: 711$ Number of nodes $\quad: 654$ Young's modulus $\quad: \mathrm{E}=2.10 \mathrm{ellPa}\left(\mathrm{N} / \mathrm{m}^{2}\right)$ Structural density $\quad: \rho_{s}=7860 \mathrm{~kg} / \mathrm{m}^{3}$ Poisson's ratio

$$
: \mu=0.3
$$

Fig. 23. Finite element modelling.

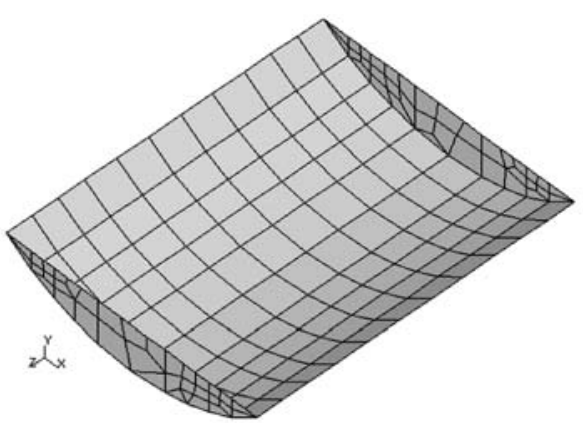

$$
\begin{array}{ll}
\text { Number of elements } & : 180 \\
\text { Number of nodes } & : 201 \\
\text { Underwater Sound } & : C=1500 \mathrm{~N} / \mathrm{s} \\
\text { Water density } & : \rho_{w}=998 \mathrm{~kg} / \mathrm{m}^{3}
\end{array}
$$

Fig. 24. Boundary element modeling on wetted surface.

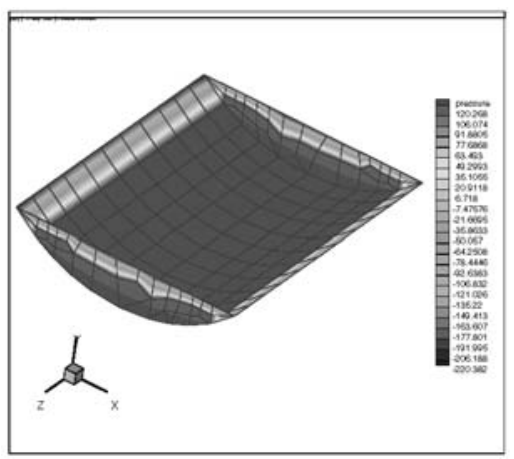

Fig. 25. Predicted sound pressure distribution on the wetted surface.

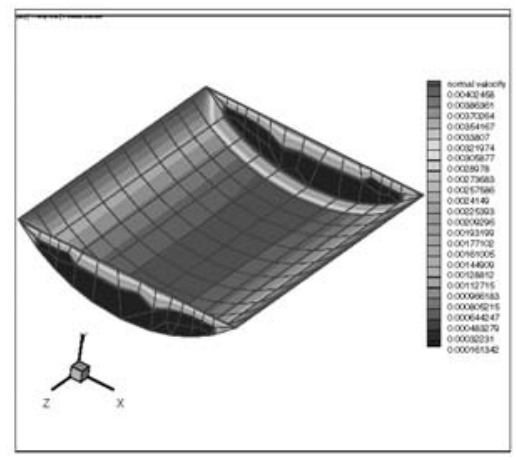

Fig. 26. Predicted normal velocity distribution on the wetted surface.

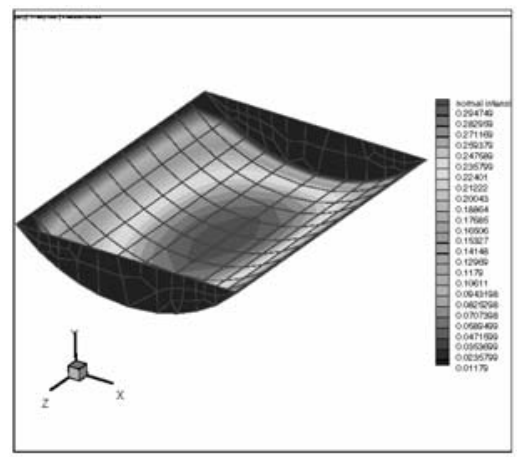

Fig. 27. Predicted sound intensity distribution on the wetted surface.

was floating on the surface cenfer of a rectangular water tank of length $4.2 \mathrm{~m}$, breadth $3.6 \mathrm{~m}$ and water depth $2.4 \mathrm{~m}$, the motor ran at $1800 \mathrm{rpm}$. The predicted distributions of pressure normal velocity, and sound intensity on the wetted surface are shown in Figs. 25-27. The prediction of underwater sound pressure on two symmetrical planes in the fluid domain and a horizontal plane at a depth 1 . $5 \mathrm{~m}$ are compared with the measured sound pressure level in Figs. 28-30.

\section{CONCLUDING REMARKS}

From the analysis and measurement works and results, it is concluded that:

1. Four-pole parameter theory for the transfer mobility analysis has validated to be credible.

2. Resilient mounts have the effects to reduce trasfer mobility, vibratory velocity and vibration power by an amount of 5-20 dB, 2-5 dB and 10-40\% respectively.

3 . The entrained mass of water apparently reduced the transfer mobility by an amount of 5-10 dB in the lower frequency range, i.e., below $1000 \mathrm{~Hz}$. 


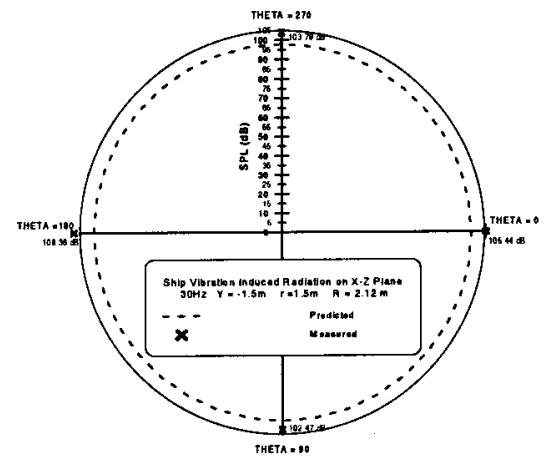

Fig. 28. Machine vibration induced underwater sound radiation at $30 \mathrm{~Hz}$ on $\mathrm{X}-\mathrm{Z}$ plane.

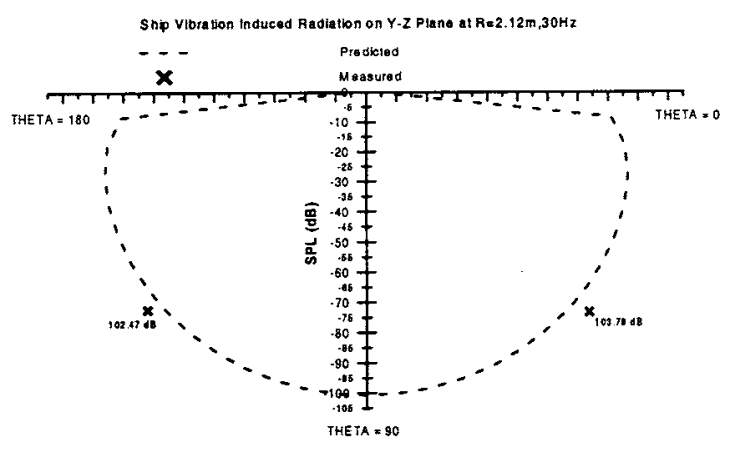

Fig. 29. Machine vibration induced underwater sound radiation at $30 \mathrm{~Hz}$ on Y-Z plane.

4. The established FEM/BEM model for structure-borne and fluid-borne sound propagation analysis has validated to be precise in comparing with the analytical solution submerged spherical shell subjected to a uniformly harmonic pressure excitation. In the case of the scaled model of engine room, there are some differences and augmentation of the far field sound pressure level between measurement and prediction. This augmentation is due to the reflection effect of the tank wall.

\section{ACKNOWLEDGEMENTS}

The authors wish to thank the support from the National Science Council of the Republic of China under contract NSC 88-2611-E-019-008 for this project.

\section{REFERENCES}

1. B. Petersson and J. Plunt, "Structure-Borne Sound Transmission from Machinery to Foundation," Report 80-19, Department of Building Acoustics, Chalmers University

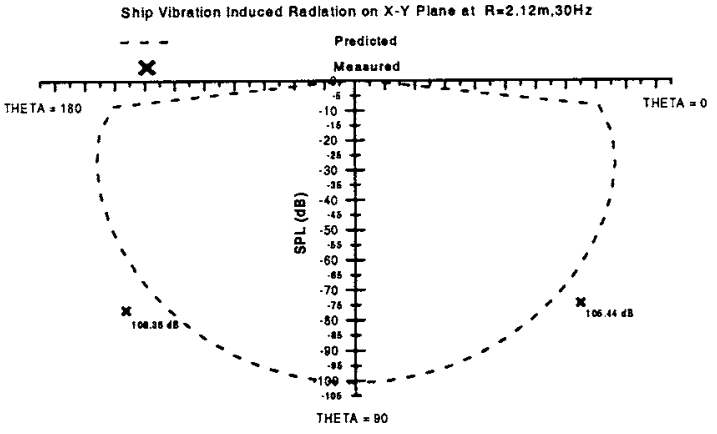

Fig. 30. Machine vibration induced underwater sound radiation at $30 \mathrm{~Hz}$ at $\mathrm{X}-\mathrm{Y}$ plane.

of Technology, Sweden (1980).

2. B.J. Dobson, R.J. Pinnington and R.G. White, "Vibrational Power Transmission Analysis of Machinery Installations in Ships with the Objective of Noise Reduction," ISVR Report 216, University of Southampton (1993).

3. W.H. Wang, R. Sutton and B. Dobson, "Vibration Reduction Behaviour Simulation of Resilient Mount by Series Double Ends Transfer Mobility," Proceedings, The 5th Conference on the Chinese Society of Sound and Vibration, 507-524 (1997).

4. B. Petersson and J. Plunt, "On Effective Mobilities in the Prediction of Structure-Borne Sound Transmission between a Source Structure and a Receiving Structure, Part I: Theoretical Background and Basic Experimental Studies," Journal of Sound and Vibration, Vol. 82, pp. 517-529 (1982).

5. B. Petersson and J. Plunt, "On Effective Mobilities in the Prediction of Structure-Borne Sound Transmission between a Source Structure and a Receiving Structure, Part II: Procedure for the Estimation of Mobilities," J. Sound \& Vibration, Vol. 82, pp. 531-540 (1982).

6. Lawrence G. Copley, "Integral Equation Method for Radiation from Vibration Bodies," The Journal of the Acoustical Society of America, Vol. 41, Num 4, pp. 807816 (1967).

7. T.W. Wu and A.F. Seybert, "A Weighted Residual Formulation for the CHIEF Method in Acoustic Radiation," The Journal of the Acoustical Society of America. 90(3), September (1991).

8. A.F. Seybert and T. K. Rengarajan, " The Use of CHIEF to Obtain Solutions for Acoustic Radiation Using Boundary Integral Equations," J. Acoust. Soc. Am., 81. pp. 1299-1306 (1987).

9. Pei-Tai Chen and Jerry H. Ginsberg, "Variational Formulation of Acoustic Radiation from Submerged Spheroidal Shells," J. Acoust. Soc. Am. 105(1), January (1999). 
10. Pei-Tai Chen, "A Modal-type Analysis of the Interactions for Submerged Elastic Structure with the Surrounding Heavy Acoustic Medium," The Journal of the Acoustical Society of America. 94(1), July (1993).

11. G.C. Everstine, "Prediction of low Frequency Vibrational Radiation of Submerged Structures," J. Vib. and Acoust., 113: 187-191 (1991).

12. Richard A. Jeans and Ian C. Mathews, "Solution of Fluid-Structure Interaction Problem Using a Coupled Finite Element and Variational Boundary Element Technique," J. Acoust. Soc. Am. 88(5), November (1990).

13. G.C. Everstine and F.M. Henderson, "Couple Finite Element/ Boundary Element Approach for Fluid-Structure Interaction," J, Acoust. Soc. Am. 87, 1947-1983 (1990).

14. R.A. Jeas and I.C. Mathews, "Solution of Fluid-Structure Interaction Problems using a Couple finite Element and Variational Boundary Element Technique," J, Acoust. Soc. Am. 88, 2466-2895 (1990).

15. Pei-Tai Chen, "Elucidation of the Relationship Between Complex Acoustic Power and Radiation Efficiency for Vibrating Bodies" J. Acoust. Soc. Am. 106(5) pp. 1-7, 11. (1999).

16. C.A. Brabbia and R.D. Ciskowski, "Boundary Element Methods in Acoustics," Computational Mechanics Publications (1991).

17. W.H. Wang, "Modelling Diesel Engine Induced Vibration Transmission in a Ship Structure," Marine Technology Dvision, Institute of Marine Studies University of Plymouth, Plymouth, Devon, March (1996).

\section{機械振動引發之水下聲音輻射}

$$
\text { 王 偉 輝 }
$$

國立台灣海洋大學系統工程暨造船學系教授

$$
\text { 劉嘉 洪 }
$$

基隆港務局舵政組技術課技士

$$
\text { 羅伯沙頓 }
$$

英國普利茅斯大學機械與輪機工程學系資深講師

$$
\text { 班道卜生 }
$$

英國丹佛皇家造船廠設計部總工程師

$$
\text { 摘 要 }
$$

本文以偶合的有限元素法／邊界元素法，來處 理結構噪音傳播與水中噪音輻射中彈性結構物與流體 之互制問題。爲改進船舶之適居性與隱匿性, 各式船 舶均需要靜音之條件, 其中由船體振動所輻射出之空 氣與水中音是主要的音源成分, 因此結構音特性之估 算在設計一艘安靜船是很重要的一件事情。利用本文 之方法對船體承受激振力後濕表面之壓力分佈及各部 振動反應可以分析, 進一步亦可評估探討船體表面之 複數功率、輻射功率及阻抗功率。

文中舉兩個數值實例, 一是浸在水中的球殼受 均匀簡諧内壓, 及另一浮於水面之機艙結構模型受馬 達激振, 分別計算其表面聲壓、法向速度、表面複數 功率、輻射功率、阻抗功率、表面振動位移響應及在 遠場的水中輻射聲型, 將此數值解與實驗量测值比 較, 顯示建立之預估模式可信。另者, 對主推進引擎 加裝彈性熱對水下噪音輻射之降低效果, 亦加以探 討。 